\title{
Microbial consumption and production of dimethyl sulfide (DMS) in the Labrador Sea
}

\author{
Gordon V. Wolfe ${ }^{*}$, Maurice Levasseur**, Guy Cantin, Sonia Michaud
}

Institut Maurice-Lamontagne, Ministère des Pêches et des Océans, CP 1000, Mont-Joli, Québec G5L. 3A1, Canada

\begin{abstract}
We examined microbial production and consumption of dimethyl sulfide (DMS) in Labrador Sea surface waters ranging in temperature from -0.1 to $6.9^{\circ} \mathrm{C}$. $200 \mathrm{nM}$ dimethyl disulfide (DMDS) was used to inhibit DMS consumption. We also studied DMS consumption kinetics by additions of 5 to $50 \mathrm{nM}$ DMS, DMS production from added dimethylsulfoniopropionate (DMSP), and DMS production and consumption during zooplankton grazing. During the cruise, DMS concentrations were low, ranging from 1 to $7 \mathrm{nM}$ throughout the study area, which included a bloom of the colonial haptophyte alga Phaeocystis pouchetii. DMDS additions often revealed rapid DMS production and consumption (up to $5 \mathrm{nM} \mathrm{d}^{-1}$ ) and very rapid turnover $(<1$ to $3 \mathrm{~d}$ ), similar to rates found in coastal waters at much higher temperatures. There was no clear effect of temperature on DMS consumption; rather, DMS consumption appeared to be tightly coupled with production. Turnover was most rapid at low DMS concentrations, and DMS consumption was stimulated by additions of DMS, or by increased DMS production from additions of dissolved DMSP. DMDS additions to zooplankton grazing incubations revealed rapid gross DMS production and consumption which were nearly balanced, resulting in net steady-state DMS patterns. DMDS did not dffect production or grazing of algal pigments or DMSP. DMS consumption saturated at 18 to 32 nM [DMS] and saturation kinetics were similar within the photic zone, but consumption was near-zero at greater depths. We suggest that DMS consumption likely saturates more easily than microbial DMS production from DMSP, and this, combined with temperature limitation on the growth of prokaryotic DMS consumers, may lead to the periodic buildup of high DMS concentrations previously observed in polar and subpolar waters.
\end{abstract}

KEY WORDS: Dimethyl sulfide - Dimethylsulfoniopropionate - DMSP - DMS - Inhibitor technique Consumption kinetics · Zooplankton grazing

\section{INTRODUCTION}

In marine surface waters, dimethyl sulfide (DMS) is thought to derive primarily from enzymatic cleavage of the algal osmolyte dimethylsulfoniopropionate (DMSP). Phytoplankton with the DMSP lyase enzyme may generate DMS either during growth (Stefels \& van Boekel 1993) or during cell lysis following grazing (Wolfe \& Steinke 1996) or viral infection (Malin et al. 1998). Bacterial cleavage of dissolved DMSP also occurs widely in the marine environment (Kiene 1990, Ledyard et al.

\footnotetext{
- Present address: College of Oceanic and Atmospheric Sciences, Oregon State University, 104 Ocean. Admin. Bldg. Corvallis, Oregon 97331-5503, USA

“Addressee for correspondence.

E-mail: levasseurm@dfo-mpo.gc.ca
}

1993, Visscher et al. 1993, Yoch et al. 1997). The relative production of DMS by eukaryotic and prokaryotic pathways is still poorly understood.

Microbial activity is also a sink for DMS in marine waters. In aerobic environments DMS is mineralized primarily to $\mathrm{CO}_{2}$ (Wolfe \& Kiene 1993b), most likely by methylotrophic bacteria such as thiobacilli or hyphomicrobia (Kelly \& Baker 1990) or facultative denitrifiers (Visscher \& Taylor 1993), although pure cultures of such organisms have so far been isolated only from sediments. In anaerobic sediments, DMS also serves as a substrate for methanogenic archaea (Oremland et al 1989, Finster et al. 1992, Ni \& Boone 1993). Since methanogenesis may occur in aerobic waters during zooplankton grazing (de Angelis \& Lee 1994), it is still not known which organisms catabolize DMS in surface waters. 


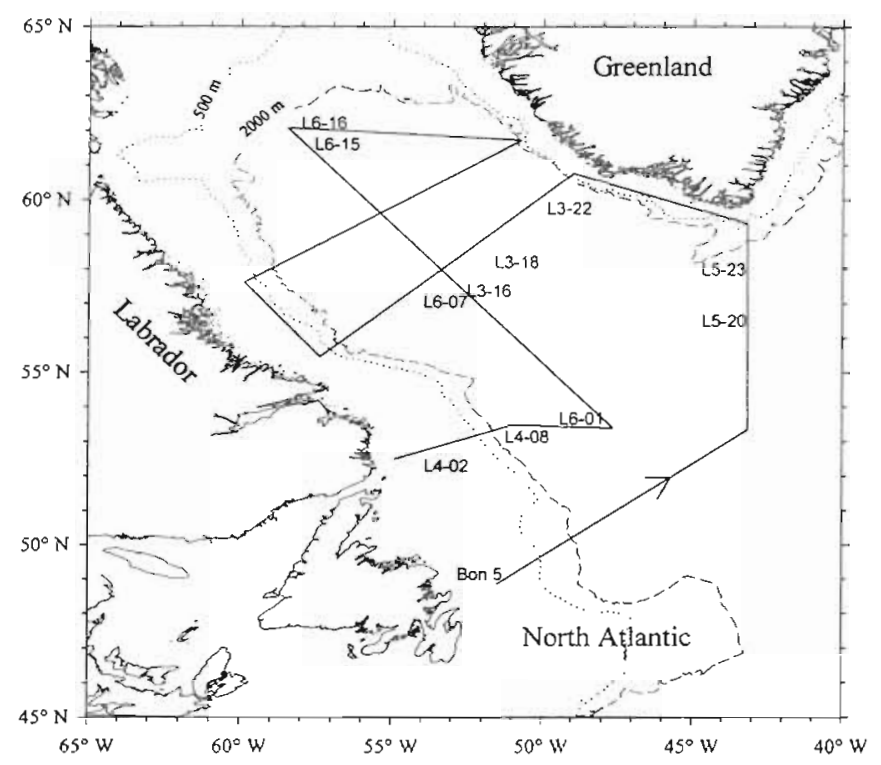

Fig. 1. Cruise track and location of sampling stations for DMS consumption incubations

Microbial DMS consumption in warm subtropical or temperate waters appears to be rapid and may significantly limit ventilation to the atmosphere (Kiene \& Bates 1990, Bates et al. 1994). DMS turnover times ranged from hours to days, based on assays with $500 \mu \mathrm{M}$ chloroform as a specific inhibitor of DMS consumption (Kiene \& Service 1991, Kiene 1992). Chloroform was subsequently found to inadvertently boost DMS production via release of DMSP from cells, resulting in overestimates of consumption rates. But tests with more specific inhibitors (dimethyl disulfide or dimethyl ether) or radioisotope methods still showed very rapid microbial consumption (Wolfe \& Bates 1993, Wolfe \& Kiene 1993b).

Although rapid microbial DMS consumption may prevent its accumulation in warm waters, DMS levels in colder temperate or polar waters can reach 10 to $100 \mathrm{nM}$ (Gibson et al. 1990, Yang et al. 1994, Turner et al. 1996), especially in association with blooms of the haptophyte alga Phaeocystis pouchetii (Barnard et al. 1984, Gibson et al. 1990, Stefels et al. 1995). Such observations suggested that microbial DMS consumption may be temperature-limited, but there have been few measurements in colder waters. Here we present results of microbial DMS consumption and production dynamics in the subpolar waters of the Labrador Sea.

\section{METHODS}

Experiments were conducted aboard the C.S.S. 'Hudson' in May-June 1997 at 12 stations located on the Newfoundland and Labrador shelfs, in the North Atlantic Drift, on the Greenland shelf, and in the Labrador basin (Fig. 1, Table 1), ranging from latitude $49^{\circ}$ to $61^{\circ} \mathrm{N}$ and longitude $44^{\circ}$ to $59^{\circ} \mathrm{W}$. A detailed description of cruise conditions and of the distribution of DMSP, DMS, and associated biological parameters will be published elsewhere.

Sampling and inhibitor additions. Water from $12 \mathrm{l}$ Niskin bottles or a side-mounted pumping system (5 1 $\mathrm{min}^{-1}$ ) was collected in an acid-rinsed $20 \mathrm{l}$ carboy. We

Table 1. Dates, conditions, and treatments for DMS production and consumption experiments conducted on the Newfoundland shelf and in the Labrador Sea in May-June 1997. nd: not determined

\begin{tabular}{|c|c|c|c|c|c|c|c|}
\hline Station & Date & $\begin{array}{l}\text { Depth } \\
\text { (m) }\end{array}$ & Water source & $\begin{array}{c}\text { Incubation } \\
T\left({ }^{\circ} \mathrm{C}\right)\end{array}$ & $\begin{array}{l}\text { In situ } \\
\mathrm{T}\left({ }^{\circ} \mathrm{C}\right)\end{array}$ & $\begin{array}{c}\text { Time } \\
\text { (h) }\end{array}$ & Treatments ${ }^{a}$ \\
\hline \multicolumn{8}{|l|}{ Newfoundland shelf } \\
\hline BON-5 & 13 May & 3 & Niskin & -0.1 & -0.1 & 24 & None \\
\hline L4-02 & 9 June & 30 & Niskin & 3.5 & 2.3 & 21 & +DMS (kinetics), +DMSPd \\
\hline \multicolumn{8}{|l|}{ North Atlantic Drift } \\
\hline L6-01 & 7 June & 20 & Pump & 4.5 & 6.9 & 48 & Grazing: light vs dark \\
\hline \multicolumn{8}{|l|}{ Labrador basin } \\
\hline L5-20 & 18 May & 3 & Pump & 5.0 & 4.5 & 18 & +DMSPd \\
\hline L5-23 & 19 May & nd & Pump & 4.5 & 3.7 & 22 & + DMSPd \\
\hline L3-22 & 22 May & 50 & Pump & 4.5 & 3.9 & 23 & $+\mathrm{GB}$ \\
\hline L3-18 & 23 May & 5 & Niskin & 4.4 & 4.4 & 48 & None \\
\hline L.3-16 & $24 \mathrm{May}$ & 3 & Niskin & 4.5 & 4.2 & 20 & +DMSPd \\
\hline L6-16 & 3 June & 20 & Pump & 3.5 & 3.6 & 24 & +DMS \\
\hline L6-15 & 4 June & 7 & Niskin & 4.5 & 4.0 & 48 & $\begin{array}{l}\text { Grazing: light vs dark, } \\
\text { copepod additions }\end{array}$ \\
\hline L6-07 & 5 June & $0 \& 30$ & Pump & 3.5 & 3.6 & 25 & +DMS (kinetics) \\
\hline L4-08 & 8 June & 70 & Pump & 6.5 & 5.0 & 21 & +DMS (kinetics) \\
\hline
\end{tabular}


were careful to minimize bubbling, to avoid degassing DMS or rupturing fragile cells, and transfers from Niskin bottles were made with Silicone tubing. Treatments were prepared, usually in duplicate, in acid-rinsed 11 polycarbonate bottles (Nalgene). DMS consumption was inhibited by addition of dimethyl disulfide (DMDS) (Wolfe \& Kiene 1993a,b). DMDS (Aldrich) was diluted volumetrically into distilled, deionized water to prepare a $1 \mathrm{mM}$ stock; this solution was kept in a sealed serum vial with minimal headspace and stored in the dark at room temperature. Aliquots were added by gastight syringe to final concentrations of 150 to $250 \mathrm{nM}$, injecting the solution slowly into incubation bottles with minimal aeration. We monitored DMDS by gas chromatography in all sample bottles to check consistency of additions and the presence of the inhibitor during the course of experiments.

Assuming that DMDS completely and selectively blocks DMS consumption, the slope of DMS versus time in the +DMDS treatment yields the gross DMS production rate, while the control bottle (-DMDS) slope yields net production minus consumption; DMS consumption rates are calculated by difference. This technique is best used with short incubation times to assure linear DMS trends, requiring good chromatographic precision: since in situ DMS levels are typically a few $n M$, even changes in DMS concentration of $<1 \mathrm{nM}$ over several hours may result in rapid turnover.

Incubation protocols. Two types of incubation experiments were conducted: (1) dark and light incubations \pm DMDS; and (2) dark incubations with DMS or dissolved DMSP (DMSPd) additions \pm DMDS. All incubations were performed in water-bath deck incubators supplied with continuously pumped surface water, whose temperatures were within $1^{\circ} \mathrm{C}$ of surface water temperature.

Dark and light incubations \pm DMDS: Samples were incubated for 6 to $48 \mathrm{~h}$ in the dark with and without DMDS additions, and changes in DMS and DMSPd were monitored at 3 to $4 \mathrm{~h}$ intervals. Three of the 12 experiments compared dark and light conditions to examine DMS production and consumption during zooplankton grazing and to determine potential sideeffects of DMDS on algal growth and zooplankton grazing rates. In these cases, samples were incubated with and without DMDS for 24 to $48 \mathrm{~h}$ in a water-bath deck incubator, either in the dark or with neutral density screening to simulate in situ light. Chl $a$, DMS and DMSP were monitored at 12 to $24 \mathrm{~h}$ intervals. On one occasion in water dominated by a bloom of colonial Phaeocystis pouchetii, we added DMDS to incubations amended with varying numbers of copepods (Calanus finmarchicus).

Dark incubation with DMS and DMSP additions: At 3 stations we amended water with 5 to $50 \mathrm{nM}$ DMS and incubated at in situ temperature for $24 \mathrm{~h}$ to determine the kinetic parameters of DMS bacterial consumption. A $400 \mu \mathrm{M}$ solution of DMS (Aldrich) was prepared in distilled water and stored in the dark at room temperature in a Teflon-sealed serum vial with minimal headspace. Aliquots of the solution were added by gastight syringe to final concentrations of 5 to $50 \mathrm{nM}$, injecting the solution slowly into incubation bottles with minimal aeration. DMDS was added to separate control (no added DMS) bottles, and DMS concentrations were measured every 6 to $12 \mathrm{~h}$ during the incubation period. Separate gastight syringes were reserved for DMS and DMDS additions throughout the cruise. On some occasions, we added DMSPd to stimulate DMS production. DMSP-Cl was prepared as a $250 \mu \mathrm{M}$ stock in distilled water, acidified with $\mathrm{HCl}$ to $\mathrm{pH} 2$ to inhibit microbial degradation, and stored at $4^{\circ} \mathrm{C}$. This was added by pipette to incubation bottles to final DMSP concentrations of 10 to $50 \mathrm{nM}$. Glycine betaine (GB, Aldrich) was added at $50 \mu \mathrm{M}$ from a $100 \mathrm{mM}$ stock solution to inhibit DMSPd uptake (Kiene \& Gerard 1995).

Chlorophyll, DMSP and DMS analyses. Chl a was extracted from Whatman GF/F-filtered cells with $90 \%$ acetone for $24 \mathrm{~h}$ at $-20^{\circ} \mathrm{C}$, then measured by a Turner Designs 111 fluorometer (Strickland \& Parsons 1972). Sulfur analyses were made by GC using a Shimadzu GC-14 chromatograph equipped with a flame photometric detector and a packed Chromosil 330 column (Supelco) operated isothermally at $60^{\circ} \mathrm{C}$; under our conditions DMS eluted at $1.2 \mathrm{~min}$ and DMDS at $6.5 \mathrm{~min}$. Detection limit was $1 \mathrm{pmol} \mathrm{S}$. Helium was used as the carrier gas and also for sparging DMS, which was cryotrapped on liquid nitrogen following passage through a Nafion drier (Permapure) to remove water vapor. Typical sparge volumes and times were 1 to $2 \mathrm{ml}$

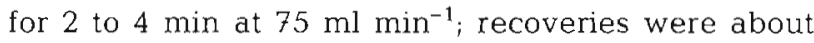
90 to $95 \%$. DMSP was analyzed by alkaline cleavage to DMS. Samples were filtered gentiy $(<5 \mathrm{~mm} \mathrm{Hg}$ ) through Whatman $\mathrm{GF} / \mathrm{F}$ filters, then the filters were quickly placed in $16 \mathrm{ml}$ serum vials containing $6 \mathrm{ml}$ of $10 \mathrm{~N} \mathrm{NaOH}$, and sealed with Teflon-lined septa. Filtrate samples were sparged to remove DMS, then $1 \mathrm{ml}$ was added to a similar vial containing $5 \mathrm{ml} 10 \mathrm{~N} \mathrm{NaOH}$ to convert DMSPd. After incubation overnight in the dark at room temperature, headspace DMS was analyzed either by direct injection $(50$ to $100 \mu \mathrm{l})$ or by flushing the headspace onto a cryotrap for $0.5 \mathrm{~min}$ at $20 \mathrm{ml} \mathrm{min}^{-1}$, and quantified by DMSP standards prepared in a similar manner.

\section{RESULTS}

Throughout the cruise, surface water temperatures ranged from $6.9^{\circ} \mathrm{C}$ at Stn L6-01 in the North Atlantic 
Drift, -0.1 to $2.3^{\circ} \mathrm{C}$ in the Labrador current on the Newfoundland shelf, and between 3.7 to $5.0^{\circ} \mathrm{C}$ at stations located in the Labrador basin (Table 1). DMS concentrations ranged from 1.5 to $7.5 \mathrm{nM}$ (Table 2). Dissolved DMSP was also low throughout the study, typically 3 to $5 \mathrm{nM}$, except for concentrations near $17 \mathrm{nM}$ at Stn BON-5.

\section{In situ DMS consumption and production}

Throughout the cruise, gross in situ DMS consumption rates varied from 0.3 to $5 \mathrm{nM} \mathrm{d}^{-1}$, and DMS production rates ranged from 0.3 to $3.8 \mathrm{nM} \mathrm{d}^{-1}$ (Table 2). The low DMS concentrations and high consumption rates resulted in surprisingly low DMS turnover times, $<1 \mathrm{~d}$ for most incubations, and rapid DMS consumption at low DMS levels appeared to be a widespread feature of the study area. One incubation (BON-5) conducted in surface waters in the Labrador current where temperature was near $-0.1^{\circ} \mathrm{C}$ gave lower DMS consumption rates even though DMS levels were relatively high, suggesting that extreme cold may inhibit DMS consumption. But another incubation in warmer

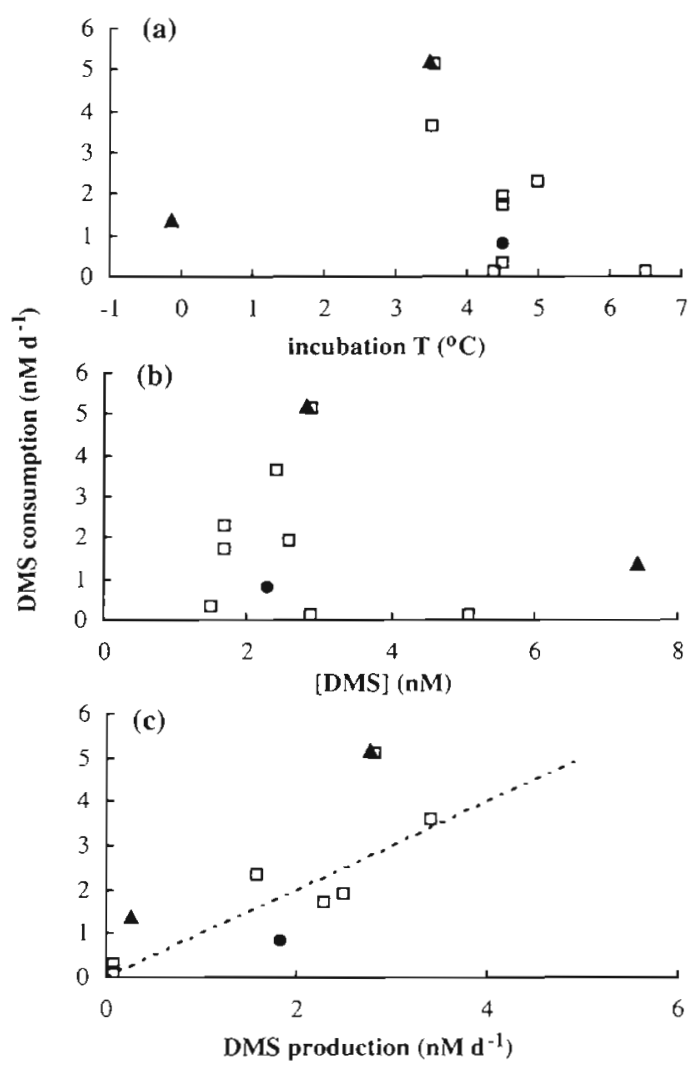

Fig. 2. Relationship between DMS consumption and (a) incubation temperature; (b) in situ [DMS]; (c) DMS production rates (dashed line is $1: 1$ ). (4) Newfoundland Shelf; (•) North Atlantic drift; ( $\square$ ) Labrador basin stations
Table 2. Results from the DMS production and consumption experiments conducted on the Newfoundland shelf and in the Labrador Sea in May-June 1997. nd: not determined

\begin{tabular}{|c|c|c|c|c|}
\hline Station & $\begin{array}{l}\text { DMS } \\
\text { (nM) }\end{array}$ & $\begin{array}{c}\text { DMS } \\
\text { production } \\
\text { rate } \\
\left(\mathrm{nM} \mathrm{d}^{-1}\right)\end{array}$ & $\begin{array}{c}\text { DMS } \\
\text { consumption } \\
\text { rate } \\
\left(n M d^{-1}\right)\end{array}$ & $\begin{array}{l}\text { DMS } \\
\text { turnover } \\
\text { time } \\
\text { (d) }\end{array}$ \\
\hline \multicolumn{5}{|c|}{ Newfoundland shelf } \\
\hline BON-5 & 7.5 & 0.3 & 1.3 & 5.6 \\
\hline L4 -02 & 2.9 & 2.8 & 5.1 & 0.6 \\
\hline \multicolumn{5}{|c|}{ North Atlantic Drift } \\
\hline L6-01 & 2.3 & $1.6-2.1$ & $0.6-1.0$ & $2.2-3.9$ \\
\hline \multicolumn{5}{|c|}{ Labrador basin } \\
\hline L5-20 & 1.7 & 1.6 & 2.3 & 0.6 \\
\hline L5-23 & 1.5 & Low & 0.3 & 6.2 \\
\hline L3-22 & $1.6-2.2$ & nd & nd & nd \\
\hline L3-18 & 5.1 & Low & Low & ca. 7 \\
\hline L3-16 & 2.6 & 2.5 & 1.9 & 1.3 \\
\hline L6-16 & 1.7 & 2.3 & 1.7 & 0.6 \\
\hline L6-15 & $1.9-2.9$ & $3.2-3.8$ & $3.6-37$ & $0.5-0.6$ \\
\hline L6-07 & 2.1 & nd & nd & nd \\
\hline $\mathrm{L} 4-08^{\mathrm{a}}$ & 2.9 & Low & Low & High \\
\hline
\end{tabular}

waters (Stn L6-01, 6.9 $9^{\circ} \mathrm{C}$ ) also gave relatively slow turnover, and in general there was no clear correlation of DMS consumption with temperature over the narrow 4 to $5^{\circ} \mathrm{C}$ range of most experiments (Fig. 2a). DMS consumption appeared to co-vary with in situ DMS concentrations (Fig. 2b) except for a few instances where consumption was low at relatively high (DMS). One of these was Labrador current water where temperature was near $-0.1^{\circ} \mathrm{C}$; another was an incubation of $70 \mathrm{~m}$ water sampled from below the chlorophyll maximum.

DMS consumption was most clearly related to DMS production: among 8 experiments, rates were linearly related $\left(\mathrm{r}^{2}=0.66\right)$ with a slope of 1.18 (Fig. 2c). These patterns suggested a tight coupling of DMS production and consumption. During many incubations, DMS concentrations in control bottles remained nearly steady, but increased in DMDS-amended bottles (Fig. 3a), implying rapid but balanced DMS production and consumption resulting in steady-state patterns. Since the inhibitor technique does not allow independent measurement of production and consumption rates, inadvertent stimulation of DMS production by inhibitors will result in overestimates of DMS consumption as well and might lead to apparent coupling of production and consumption which is an artifact. However, several observations suggest that these patterns were not artificial. In a few instances DMS concentrations decreased in control bottles and remained steady in DMDS-amended bottles, implying little DMS produc- 
tion and rapid consumption (Fig. 3b). When DMS consumption was occasionally low (Stn L5-20), it increased following addition of dissolved DMSP, which boosted DMS production (Fig. 4). Finally, during zooplankton grazing experiments, additions of 200 nM DMDS did not significantly affect production or removal of DMSPp or chlorophyll (not shown), indicating it had a minimal impact on phytoplankton growth or microzooplankton grazing. There, we believe that DMDS inhibition of DMS consumption did not grossly affect biological activity and the close link between DMS production and consumption is not an artifact.

\section{DMS consumption kinetics}

Additions of 7 to 40 nM DMS stimulated consumption (Fig. 5a, light symbols). DMDS blocked consumption of added DMS (Fig. 5a, dark symbols) and revealed DMS production, which was independent of added DMS (Fig. 5b). We found saturation of DMS consumption at 10 to $30 \mathrm{nM}$ (DMS) (Fig. 5b), with apparent $\mathrm{Ks}$ and $V m$ values of ca. $9 \mathrm{nM}$ and $11 \mathrm{nM} \mathrm{d}^{-1}$, respectively. Turnover was 100 to $200 \% \mathrm{~d}^{-1}$ at in situ [DMS] but fell to 20 to $40 \% \mathrm{~d}^{-1}$ at $30 \mathrm{nM}$ (DMS) (Fig. 5c). Several experiments in different locations gave similar kinetic patterns (Table 3), which are similar to those found with radioisotope and inhibitor methods for subtropical coastal waters (Kiene \& Service 1991, Wolfe \& Kiene 1993b). On one occasion we compared water from 3 and $30 \mathrm{~m}$ and found very similar kinetic profiles (Fig. 6a), but in another experiment, water from $70 \mathrm{~m}$ (well below the chlorophyll maximum) showed no consumption of 7 to $50 \mathrm{nM}$ DMS additions (Fig. 6b).

\section{DMS production and consumption during zooplankton grazing}

In grazing (dilution) experiments without inhibitors (Wolfe et al. unpubl.), DMS usually remained in steadystate over 24 to $48 \mathrm{~h}$ incubations and appeared decou-

Table 3. DMS consumption Michaelis-Menten kinetic parameters (half-saturation concentration and saturation consumption), calculated from $1 / \mathrm{V}$ vs $1 /[\mathrm{S}]$

\begin{tabular}{|cccc|}
\hline Station & $\begin{array}{c}\text { Sampling depth } \\
(\mathrm{m})\end{array}$ & $\begin{array}{c}\mathrm{Ks} \\
(\mathrm{nM})\end{array}$ & $\begin{array}{c}\mathrm{Vm} \\
\left(\mathrm{nM} \mathrm{d}^{-1}\right)\end{array}$ \\
\hline L4-02 & 30 & 9.4 & 11.2 \\
L6-07 & 0 & 14.4 & 24.0 \\
L6-07 & 30 & 16.1 & 25.3 \\
L4-08 & 70 & No consumption \\
\hline
\end{tabular}
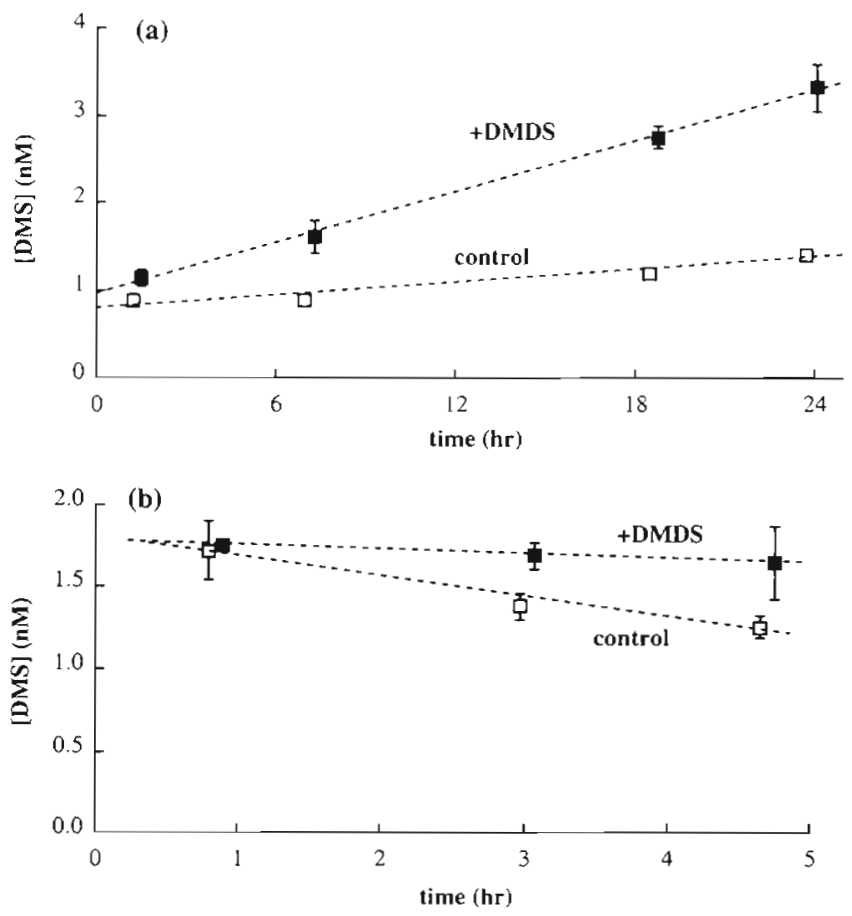

Fig. 3. Examples of DMS dynamics with and without $250 \mathrm{nM}$ DMDS. (a) Stn L6-16 (3 Jun 1997), showing balanced production and consumption in control bottles but apparent production with DMDS added; (b) Stn L5-20 (18 May 1997) showing rapid consumption without DMDS. Data are means of replicate bottles, with ranges given by error bars. Dashed lines are linear regressions

pled from manipulations of grazing rate. However, this was likely a result of rapid but balanced DMS production and consumption, since we subsequently found that DMDS additions during grazing incubations often resulted in rapid accumulation of DMS (Fig. 7a). This

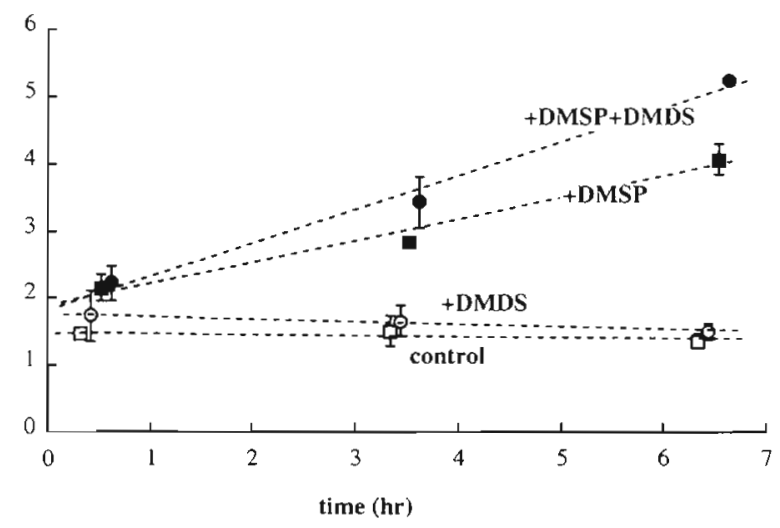

Fig. 4. Stimulation of DMS consumption following increase of DMS production from added DMSPd. Stn L5-23 (19 May 1997). Data are means of replicate bottles, with ranges given by error bars. Dashed lines are linear regressions 


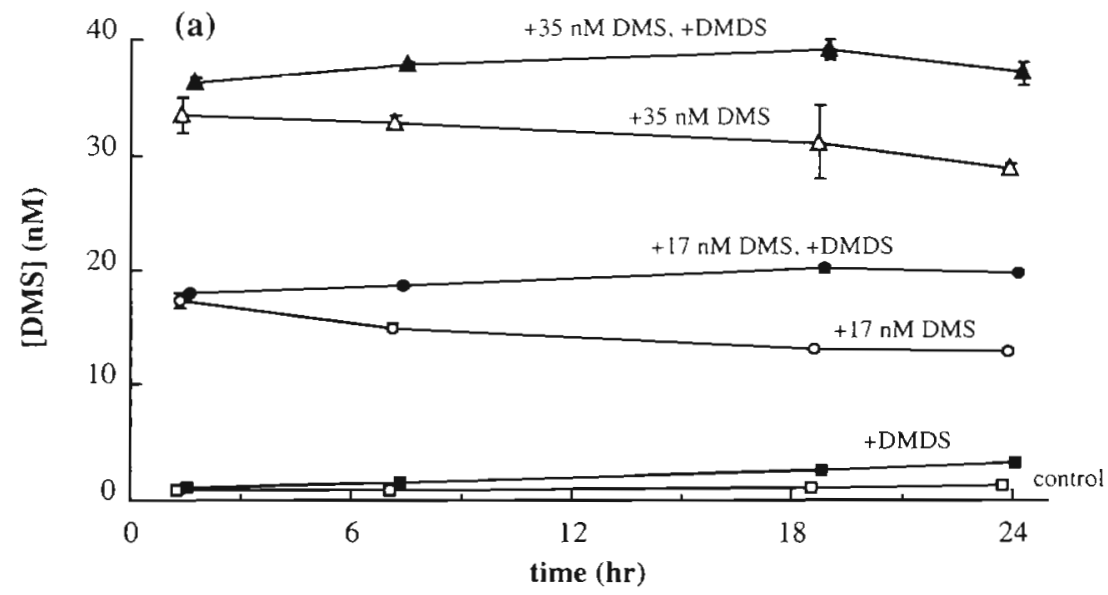

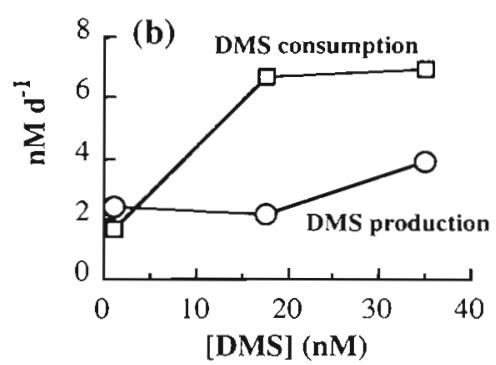

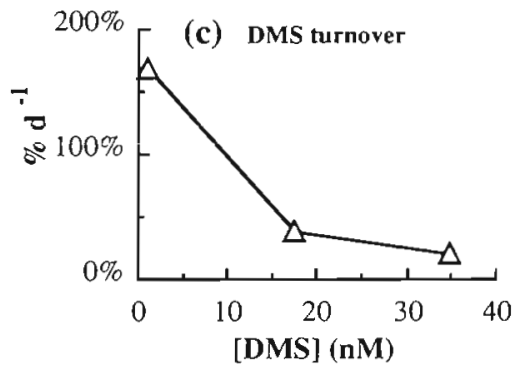

Fig. 5. Example of DMS consumption kinetics (Stn L6-16; 3 Jun 1997; $20 \mathrm{~m}$ water). (a) time course for bottles with DMS additions of 0,17 , and $35 \mathrm{nM} \pm$ DMDS. Light symbols: -DMDS; dark symbols: +DMDS. Data are means of replicate bottles, with ranges given by error bars. (b) Calculated DMS consumption and production rates vs total DMS based on linear regressions of (a); (c) Calculated DMS turnover vs total DMS trend was not affected by the presence or absence of light, suggesting that photooxidation of DMS was negligible compared to biological removal. We also performed a grazing experiment with additions of the copepod Calanus finmarchicus to water sampled from a bloom of colonial Phaeocystis pouchetii, where DMS levels were low, about 3 to $6 \mathrm{nM}$, despite abundant (200 to $400 \mathrm{nM}$ ) algal DMSP. Again, DMDS additions did not alter removal of algal DMSP or chlorophyll (not shown) but revealed a high DMS production rate, matched by nearly equal consumption (Fig. $7 \mathrm{~b}$ ).

\section{DISCUSSION}

As measured by the DMDS inhibitor technique, rapid microbial DMS consumption appeared to be a consistent feature in these waters $<6^{\circ} \mathrm{C}$ where DMS concentrations ranged from 1.5 to $7.5 \mathrm{nM}$. We were surprised to find in situ DMS turnover times $<1 \mathrm{~d}$ in many instances, similar to observations in much warmer waters by radioisotope (Wolfe \& Kiene 1993b) and inhibitor (Kiene 1992) methods. We caution that the inhibitor technique does not allow independent measurement of production and consumption rates, and inadvertent stimulation of DMS production by inhibitors will result in overestimates of DMS con- sumption as well. Wolfe \& Kiene (1993b) found that 100 nM DMDS appeared to be a much more selective inhibitor for DMS consumption than $500 \mu \mathrm{M}$ chloroform and produced fewer artifacts. In this study, DMDS additions did not affect such processes as bulk algal growth or zooplankton grazing, but we did not compare DMDS inhibitor results with other inhibitors or radioisotope methods.

Several observations indicated DMS consumption was closely linked to its production (Fig. 2c). Water from within the euphotic zone showed similar kinetic profiles but water from the base of the euphotic zone, below the chlorophyll maximum, showed essentially no consumption (Fig. 6). DMS consumption in grazing incubations was very rapid (Fig. 7), masking production unless inhibitors were added. Limited additions of DMS, or elevated DMS production (by additions of DMSPd) increased consumption as well (Fig. 4), tending to drive the system in the direction of equilibrium. These results all reinforce the suggestion by Kiene \& Service (1991) that build-up of DMS may cause an increase in the abundance and/or activity of DMS-consuming bacteria or enzyme systems, a process Levasseur et al. (1996) have termed 'bio-conditioning', which tends to maintain DMS at low levels. At low DMS concentrations, DMS consumption may limit DMS accumulation and outgassing in temperate and 
colder waters, as well as in warmer regions (Kiene \& Bates 1990).

\section{Limitations on microbial DMS consumption in cold waters}

In contrast to our observations, prior studies suggest that the balance between DMS production and consumption occasionally fails at high latitudes, leading to episodic pulses of DMS and increasing ventilation to the atmosphere as a sink. Seasonal bursts of very high DMS - sometimes reaching $100 \mathrm{nM}$ or higher-are a consistent feature of polar and subpolar waters, especially during or following Phaeocystis blooms (Gibson et al. 1990, 1996, Yang et al. 1992, Crocker et al. 1995). Our observations suggest several factors which might contribute to such patterns: differences in DMS production and consumption kinetics, and temperature limitations on DMS consumption.

Several studies of DMSP cleavage by marine bacterial isolates has shown saturation kinetics at or above $\mu$ M DMSP levels (Ledyard \& Dacey 1994, de Souza \& Yoch 1995), and studies of DMS production from dissolved DMSP in marine surface waters have also found saturation well above ambient dissolved DMSP levels (Kiene \& Service 1991, Kiene 1992, Ledyard \& Dacey $1996 \mathrm{a}, \mathrm{b})$. Such a pattern was also seen in our study (Shultes et al.
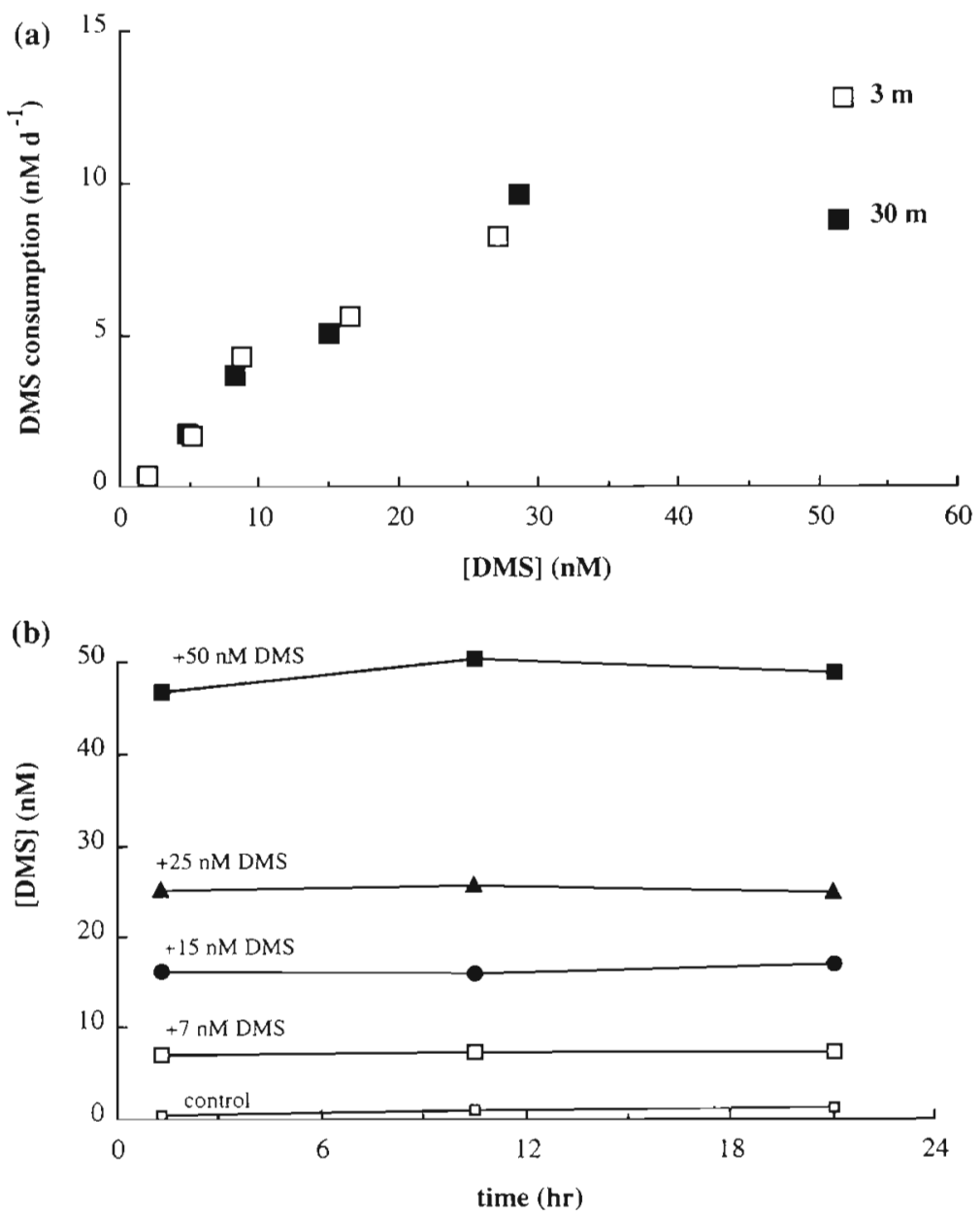

Fig. 6. (a) Comparison of DMS consumption kinetics in 3 and $30 \mathrm{~m}$ water (Stn L6-07, 6-5-97), showing similar kinetic profiles within a mixed layer. (b) DMS additions to water from below the chlorophyll maximum (Stn L4-08, 8 Jun $1997,70 \mathrm{~m}$ ), showing no DMS consumption activity
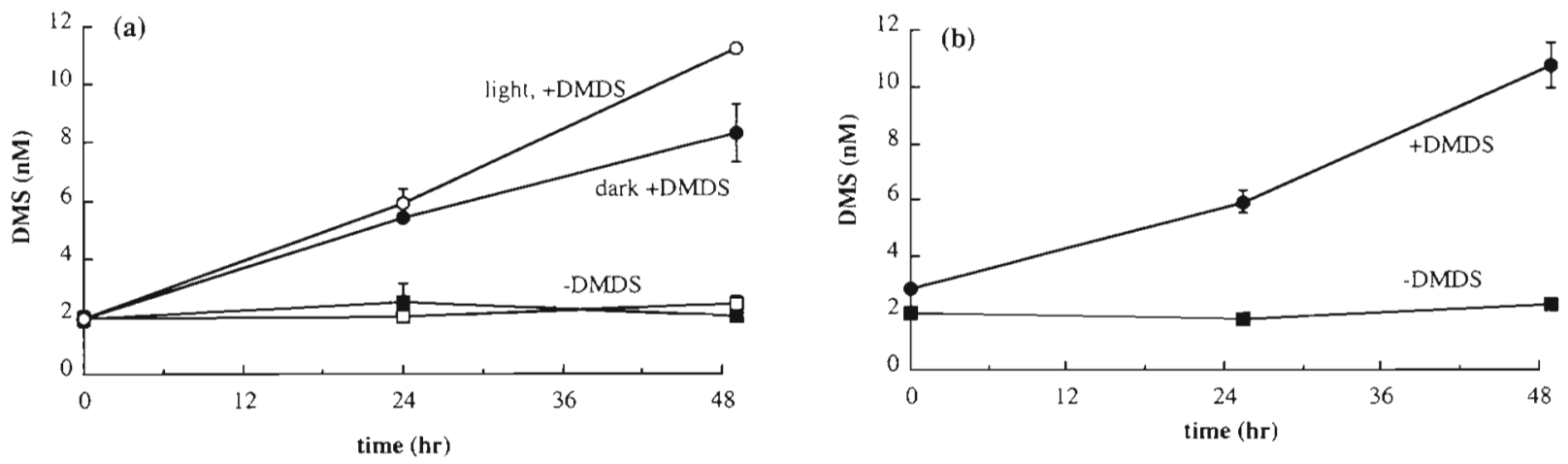

Fig. 7. DMS production during zooplankton grazing, as revealed by DMDS addition. (a) Light/dark incubation, Stn L6-01, 7 Jun 1997, $20 \mathrm{~m}$ water $\left(4.5^{\circ} \mathrm{C}\right)$. Open symbols are incubations in light; filled symbols are dark bottles. (b) Addition of copepods (Calanus finmarchicus, 10 animals $1^{-1}$ ) to surface water with colonial Phaeocystis pouchetii bloom (Stn L6-15, 4 Jun 1997, 7 m water, ca $10^{7}$ cells $\mathrm{l}^{-1}$ ). Data are means of replicate bottles, with ranges given by error bars 
unpubl.). In vivo DMS production kinetics by the alga Phaeocystis pouchetii (Stefels \& Dijkhuizen 1996), which appears to have a cell-surface DMSP lyase and can cleave exogenous DMSP (Stefels \& van Boekel 1993) saturated only at $>30 \mu M$ DMSPd, so eukaryotic production of DMS may also saturate well above low nM DMSPd concentrations. In contrast, results from this study and others in warmer waters (Kiene \& Service 1991, Kiene 1992, Wolfe \& Kiene 1993b, Ledyard \& Dacey 1996b) consistently find DMS consumption saturates at 10 to $30 \mathrm{nM}$ DMS. Therefore, differences in DMS production and consumption kinetics may cause the tight coupling seen at low DMS levels to break down when DMS production increases. It was clear from additions of dissolved DMSP or DMS that DMS consumption could be easily overwhelmed: additions of 7 to 50 nM DMS increased DMS consumption, but not sufficiently to completely restore equilibrium within 24 h (Figs. 4 \& 5a).

Breakdown of the coupling of DMS production and consumption at high latitudes may also be due to temperature limitation on DMS consumption, since algal production of DMS may increase at low temperatures (Baumann et al. 1994). Temperature limitation on DMS consumption might be due either to direct effects on enzyme systems, or from limitation of microbial growth rates. Since we found rapid consumption of low DMS concentrations in 4 to $5^{\circ} \mathrm{C}$ waters, we hypothesize that temperature limitation might affect the growth of DMS-consuming microbial populations, reducing their ability to respond to high pulses of DMS production. The effects of low temperature on bacterial growth and activity is still controversial: it is unclear whether temperature or substrate levels limit growth in cold waters (Pomeroy \& Deibel 1986, Pomeroy et al. 1991). Recent evidence suggest that bacterial growth is generally substrate limited, but temperature limitation becomes important at saturating substrate concentrations (Wiebe et al. 1992, Nedwell \& Rutter 1994, Rutter \& Nedwell 1994). Although we have no direct measurements of bacterial growth rates, we observed near-linear removal of DMS over $24 \mathrm{~h}$ in DMS addition incubations at 4 to $6^{\circ} \mathrm{C}$ (Fig. 5a), whereas incubations in warmer waters often show increasing removal of DMS over time, likely due to growth of consumers (see for example Fig. 9 in Kiene \& Service 1991).

Therefore, we hypothesize that in colder waters, the lower temperature and kinetic sensitivity of eukaryotic DMS production may at times combine to outstrip DMS consumption, leading to the high pulses of DMS observed. In this study we were not able to separate bacterial DMS production from eukaryotic production pathways: attempts to inhibit bacterial DMSPd uptake by additions of $50 \mu \mathrm{M}$ glycine betaine did not yield consistent results, possibly due to its transient effect
(Kiene \& Gerard 1995) in our relatively long incubations. We also did not explicitly examine the effects of temperature on DMS production and consumption. Clearly, further study of DMS production and consumption dynamics in cold waters will be necessary to determine the constraints which prevent or allow build-up of high DMS seen at high latitudes

Acknowledgements. We thank Erica Head for use of the deck incubator, Evelyn and Barry Sherr for loan of analytical equipment and supplies, Allyn Clarke and the crew of the C.S.S. 'Hudson' for logistical support, and Les Harris and Jeff Anning for pump water samples and technical advice. Ron Kiene kindly shared unpublished data on microbial DMS consumption, and Evelyn and Barry Sherr provided insights on temperature limitations on prokaryotes versus eukaryotes. We also thank 3 anonymous reviewers for helpful comments on the manuscript. This project was supported by grants from the Department of Fisheries and Ocean Canada (Northern Ocean DMS Emission Models - NODEM) and the Natural Sciences and Engineering Research Council of Canada (NSERC).

\section{LITERATURE CITED}

Barnard WR, Andreae MO, Iverson RL (1984) Dimethylsulfide and Phaeocystis pouchetii in the southeastern Bering Sea. Cont Shelf Res 3:103-113

Bates TS, Keine RP, Wolfe GV, Matrai PA, Chavez FP, Buck KR, Bloomquist BW, Cuhel RL (1994) The cycling of sulfur in surface seawater of the northeast Pacific. J Geophys Res 99:7835-7843

Baumann MEM, Brandini FPB, Staubes R (1994) The influence of light and temperature on carbon-specific DMS release by cultures of Phaeocystis antarctica and three antarctic diatoms. Mar Chem 45:129-136

Crocker KM, Ondrusek ME, Petty RL, Smith RC (1995) Dimethylsulfide, algal pigments and light in an Antarctic Phaeocystis sp. bloom. Mar Biol 124:335-340

de Angelis MA, Lee C (1994) Methane production during zooplankton grazing on marine phytoplankton. Limnol Oceanogr 39:1298-1308

de Souza MP, Yoch DC (1995) Purification and characterization of dimethylsulfoniopropionate lyase from an Alcaligenes-like dimethyl sulfide producing marine isolate. Appl Environ Microbiol 61:21-26

Finster $\mathrm{K}$, Tanimoto $\mathrm{Y}, \mathrm{Bak} F$ (1992) Fermentation of methanethiol and dimethylsulficle by a newly isolated methanogenic bacterium. Arch Microbiol 157:425-430

Gibson JAE, Garrick RC, Burton HR, McTaggart AR (1990) Dimethylsulfide and the alga Phaeocystis pouchetii in Antarctic coastal waters. Mar Biol 104:339-346

Gibson JAE, Swadling KM, Burton HR (1996) Acrylate and dimethylsulfoniopropionate (DMSP) concentrations during an Antarctic phytoplankton bloom. In: Kiene RP, Visscher $P$, Kirst $G$, Keller M (eds) Biological and environmental chemistry of DMSP and related sulfonium compounds. Plenum Press, New York, p 213-222

Kelly DP, Baker SC (1990) The organosulphur cycle: aerobic and anaerobic processes leading to turnover of $\mathrm{C}_{1}$-sulphur compounds. FEMS Microbiol. Rev 87:241-246

Kiene RP (1990) Dimethyl sulfide production from dimethylsulfoniopropionate in coastal seawater and bacterial cultures. Appl Environ Microbiol 56:3292-3297 
Kiene RP (1992) Dynamics of dimethyl sulfide and dimethylsulfoniopropionate in oceanic water samples. Mar Chem $37: 29-52$

Kiene RP, Bates TS (1990) Biological removal of dimethyl sulfide from seawater. Nature 345:702-705

Kiene RP, Gerard G (1995) Evaluation of glycine betaine as an inhibitor of dissolved dimethylsulfoniopropionate degradation in coastal waters. Mar Ecol Prog Ser 128:121-131

Kiene RP, Service SK (1991) Decomposition of dissolved DMSP and DMS in estuarine waters: dependence on temperature and substrate concentration. Mar Ecol Prog Ser $76: 1-11$

Ledyard KM, Dacey JWH (1994) Dimethylsulfide production from dimethylsulfoniopropionate by a marine bacterium. Mar Ecol Prog Ser 110:95-103

Ledyard KM, Dacey JWH (1996a) Kinetics of DMSP-lyase activity in coastal seawater. In: Kiene RP, Visscher P, Kirst $G$, Keller M (eds) Biological and environmental chemistry of DMSP and related sulfonium compounds. Plenum Press, New York, p 325-335

Ledyard KM, Dacey JWH (1996b) Microbial cycling of DMSP and DMS in coastal and oligotrophic seawater. Limnol Oceanogr 41:33-40

Ledyard KM, DeLong EF, Dacey JWH (1993) Characterization of a DMSP-degrading bacterial isolate from the Sargasso Sea. Arch Microbiol 160:312-318

Levasseur M, Michaud S, Egge J, Cantin G, Nejstgaard JC Sanders R, Fernandez E, Solberg PT, Heimdal B, Gosselin M (1996) Production of DMSP and DMS during a mesocosm study of an Emiliania huxleyi bloom: influence of bacteria and Calanus finmarchicus grazing. Mar Biol 126 $609-618$

Malin G, Wilson WH, Bratbak G, Liss PS, Mann NH (1998] Elevated production of dimethylsulfide resulting from viral infection of Phaeocystis pouchetii. Limnol Oceanogr 43:1389-1393

Nedwell DB, Rutter M (1994) Influence of temperature on growth rate and competition between two psychrotolerant Antarctic bacteria: low temperature diminishes affinity for substrate uptake. Appl Environ Microbiol 60:1984-1992

Ni S, Boone DR (1993) Catabolism of dimethylsulfide and methane thiol by methylotrophic methanogens. In: Oremland RS (ed) The biogeochemistry of global change: radiatively active trace gases. Chapman and Hall, New York, p 796-810

Oremland RS, Kiene RP, Mathrani I, Whiticar MJ, Boone DR (1989) Description of an estuarine methylotrophic methanogen which grows on dimethyl sulfide. Appl Environ Microbiol 55:994-1002

Pomeroy LR, Deibel D (1986) Temperature regulation of bacterial activity during the spring bloom in Newfoundland coastal waters. Science 233:359-361

Pomeroy LR, Wiebe WJ, Diebel D, Thompson RJ, Rowe GT, Pakulski JD (1991) Bacterial responses to temperature and substrate concentration during the Newfoundland spring bloom. Mar Ecol Prog Ser 75:143-159

Rutter M, Nedwell DB (1994) Influence of changing temperature on growth rate and competition between two psy-

Editorial responsibility: Farooq Azam,

La Jolla, California, USA chrotolerant Antarctic bacteria: competition and survival in non-steady state temperature environments. Appl Environ Microbiol 60:1993-2002

Stefels J, Dijkhuizen L. (1996) Characteristics of DMSP-lyase in Phaeocystis sp. (Prymnesiophyceae). Mar Ecol Prog Ser 131:307-313

Stefels J, van Boekel WHM (1993) Production of DMS from dissolved DMSP in axenic cultures of the marine phytoplankton species Phaeocystis sp. Mar Ecol Prog Ser 97 $11-18$

Stefels J, Dijkhuizen L, Gieskes WWC (1995) DMSP-lyase activity in a spring phytoplankton bloom off the Dutch coast, related to Phaeocystis sp. abundance. Mar Ecol Prog Ser 123:235-243

Strickland JHD, Parsons TR (1972) A practical handbook of seawater analysis. Bull Fish Res Bd Can 167:1-310

Turner SM, Malin G, Nightingale PD, Liss PS (1996) Seasonal variation of dimethyl sulphide in the North Sea and an assessment of fluxes to the atmosphere. Mar Chem 54: $245-262$

Visscher PT, Taylor BF (1993) A new mechanism for the aerobic catabolism of dimethyl sulfide. Appl Environ Microbiol 59:3784-3789

Visscher PT, Diaz MR, Taylor BF (1993) Enumeration of bacteria which cleave or demethylate dimethylsulfoniopropionate in the Caribbean Sea. Mar Ecol Prog Ser 89: 293-296

Wiebe WJ, Sheldon WM Jr, Pomeroy LR (1992) Bacterial growth in the cold: evidence for an enhanced substrate requirement. Appl Environ Microbiol 58:359-364

Wolfe GV, Bates TS (1993) Biological consumption of dimethyl sulfide (DMS) in the marine euphotic zone: results of radioisotope experiments. In: Oremland RS (ed) Biogeochemistry of global change: radiatively active trace gases. Chapman and Hall, New York, p. 691-703

Wolfe GV, Kiene RP (1993a) Effects of methylated, organic, and inorganic substrates on microbial consumption of dimethyl sulfide in estuarine waters. Appl Environ Microbiol 59:2723-2726

Wolfe GV, Kiene RP (1993b) Radioisotope and chemical inhibitor measurements of dimethyl sulfide consumption rates and kinetics in estuarine waters. Mar Ecol Prog Ser 99:261-269

Wolfe GV, Steinke M (1996) Grazing-activated production of dimethyl sulfide (DMS) by two clones of Emiliania huxleyi. Limnol Oceanogr 41:1151-1160

Yang H, McTaggart AR, Davidson AT, Burton H (1992) Natural productivity of acrylic acid and dimethyl sulphide during a summer bloom of Phaeocystis pouchetii in Antarctic coastal water. Antarctic Res 3:26-43

Yang H, McTaggart AR, Davidson AT, Burton H (1994) Measurement of acrylic acid and dimethyl sulfide in Antarctic coastal water during a summer bloom of Phaeocystis pouchetii. Proc MIPR Symp Polar Biol 7:43-52

Yoch DC, Ansede JH, Rabinowitz KS (1997) Evidence for intracellular and extracellular dimethylsulfoniopropionate (DMSP) lyases and DMSP uptake sites in twro species of marine bacteria. Appl Environ Microbiol 63:3182-3188

Submitted: July 11, 1998; Accepted: November 20, 1998

Proofs received from author(s): July 22, 1999 